\title{
SER PORTADOR DE HEPATITE C: SENTIMENTOS E EXPECTATIVAS ${ }^{1}$ BEING A HEPATITIS C CARRIER: FEELINGS AND EXPECTATIVES PACIENTE CON HEPATITIS C: SENTIMIENTOS Y EXPECTATIVAS
}

\author{
Valdeth Vieira de Sousa², Karla Prado de Souza Cruvinel ${ }^{3}$
}
${ }^{1}$ Trabalho de Conclusão de Curso para obtenção do título de Bacharel em Enfermagem pelo Centro Universitário de Anápolis/ UniEVANGÉLICA.
${ }^{2}$ Graduanda em Enfermagem pelo Centro Universitário de Anápolis/UniEVANGÉLICA. Goiás, Brasil.
${ }^{3}$ Mestre em Medicina Tropical. Professor Adjunto do curso de Enfermagem do Centro Universitário de Anápolis/ UniEVANGÉLICA. Goiás, Brasil.

PALAVRAS-CHAVE: Hepatite C. Hepacivirus. Qualidade de vida.
RESUMO: A hepatite C é uma doença infecciosa, com elevado potencial de evolução para cirrose e/ ou carcinoma hepatocelular, que cursa silenciosamente, implicando ao seu portador um prognóstico obscuro em que o indivíduo é um ser doente sem nada sentir. Objetivou-se descrever a vivência de pessoas portadoras do vírus da hepatite $C$ relacionada à infecção e suas conseqüências. Desenvolveu-se um estudo qualitativo em uma instituição hospitalar pública de Goiânia-GO, especializada em doenças infecto-contagiosas. Foram entrevistados oito sujeitos no mês de agosto de 2007, e os dados analisados pela técnica de análise de conteúdo temático. A partir da análise, emergiram três categorias: sofrimento e impotência frente à infecção; luta e dificuldades enfrentadas; e fé como força motivadora. Nota-se que o sofrimento desses indivíduos está relacionado à patologia de base e aos efeitos colaterais do tratamento que levam a mudanças de vida, contudo, buscam na fé uma força motivadora.
KEYWORDS: Hepatitis C. Hepacivirus. Quality of life.

PALABRAS CLAVE: Hepatitis C. Hepacivirus. Calidad de vida.
ABSTRACT: Hepatitis $C$ is an infectious disease with elevated potential of developing into cirrhosis and/or hepatocellular carcinoma, which acts silently, offering its bearers a dark prognosis in which they are sick without feeling a thing. In order to describe life for people with hepatitis C related to infection and its consequences, a qualitative study was developed in a public hospital specialized in contagious diseases in Goiânia-GO, Brazil. Eight people were interviewed in August of 2007, and the data was analyzed by the thematic content analysis technique. From this analysis three categories emerged: suffering and impotence facing infection, fighting and difficulties faced, and faith as a motivating power. It was noted that these individuals' suffering is related to base pathology and side effects from treatment, which lead to life changes. However, they find in faith a motivating power.
RESUMEN: La hepatitis $C$ es una enfermedad infectocontagiosa, con alto potencial evolutivo para cirrosis y/o carcinoma hepatocelular, que ataca silenciosamente, provocando que el enfermo tenga un pronóstico preocupante, ya que el individuo está enfermo, sin sentir nada. Para describir la vivencia de personas que tienen el virus de la hepatitis $C$ relacionadas a la infección y sus consecuencias, fue desarrollado un estudio cualitativo en una institución hospitalaria pública de Goiânia-GO, especializada en enfermedades infectocontagiosas. Fueron entrevistados ocho sujetos en el mes de agosto de 2007, y sus datos fueron analizados por la técnica de análisis de contenido temático. A partir del análisis surgieron tres categorías: sufrimiento e impotencia ante la infección, lucha y dificultades enfrentadas, $y$, la fe como fuerza motivadora. Es perceptible que el sufrimiento de esos individuos está relacionado con la patología de base y con los efectos colaterales del tratamiento, los cuales provocan cambios de vida, sin embargo, ellos buscan en la fe, una fuerza motivadora.
Karla Prado de Souza Cruvinel

Centro Universitário de Anápolis/UniEVANGÉLICA

Endereço: Av. Universitária km 3,5

75070-290 - Cidade Universitária, Anápolis, GO, Brasil

E-mail: karlaprado@unievangelica.edu.br
Artigo original: Pesquisa

Recebido em: 31 de março de 2008 Aprovação final: 13 de outubro de 2008 


\section{INTRODUÇÃO}

A hepatite $C$ é uma doença infecciosa que traz grandes desafios à ciência. Os conhecimentos acerca dessa infecção vêem se desenvolvendo constantemente desde a identificação de seu agente etiológico em 1989. ${ }^{1}$

A infecção pelo Vírus da Hepatite C (VHC) apresenta distribuição universal acometendo 3\% da população mundial, o que representa aproximadamente 170 milhões de pessoas, sendo queno Brasil, a prevalência oscila entre 2,5 a 10\%. ${ }^{2}$ Assim, a importância e a relevância clínica do estudo da infecção pode ser traduzida pelo número de indivíduos infectados, pela alta taxa de cronificação $(80 \%)$ e assintomatologia (95\%). ${ }^{3}$

Além das altas taxas de cronicidade e potencial evolutivo para cirrose e hepatocarcinona, atribui-se também à hepatite $\mathrm{C}$, a inexistência de imunoprofilaxia preventiva. Essas características aliadas à dificuldade de resposta ao tratamento e, por ser ainda uma infecção oculta, em que a maioria dos portadores desconhece albergar o vírus, faz com que a infecção pelo vírus da hepatite $C$ constitua-se em um grave problema de Saúde Pública. ${ }^{1}$

As doenças hepáticas crônicas por hepatite C são a sétima causa de anos de vida perdidos entre os homens e a décima segunda entre as mulheres. Constitui-se por ser o maior motivo de indicação para transplante hepático e principal causadora de cirrose no mundo, competindo com a hepatite alcoólica como importante causa de doença crônica do fígado. ${ }^{4}$

Embora seja uma infecção progressiva que cursa lentamente, pode ser fatal e grave. $\mathrm{O}$ tratamento requer período de tempo prolongado tendo como características a baixa erradicação viral associada a pouca segurança terapêutica o que o inviabiliza para um grande número de portadores, sendo esses acompanhados de forma expectante. ${ }^{3-4}$ Alguns indivíduos não respondem satisfatoriamente ao tratamento, ou ainda podem não manter resposta sustentada, tornando-se recidivantes. Esses óbices estão na dependência do genótipo, bem como podem estar relacionados à especificidade e sensibilidade dos métodos diagnósticos empregados. ${ }^{5}$

Sabe-se que as doenças crônicas implicam uma ruptura do modo de vida, alterações psicológicas e comportamentais, exigindo do indivíduo uma atitude de repensar em seus hábitos e como enfrentar essa nova realidade. ${ }^{4}$ Quanto à hepatite $C$, essas alterações podem ser resultantes tanto da patologia de base como das implicações terapêuticas. Percebe-se ainda na sociedade em geral, uma indiferença e subestimação acerca da potencialidade noxa do VHC, um inimigo tão devastador quanto o Vírus da Imunodeficiência Humana (HIV). Essa realidade modifica-se quando os indivíduos descobrem-se como portadores desse agente viral. Frente a essa nova situação, faz-se necessário o processamento de inúmeras alterações no cotidiano dessas pessoas. A nova experiência vivencial repercute em trauma emocional traduzido por alguns em sentimentos de ansiedade, depressão, medo, raiva e culpa. ${ }^{6}$ Nesse sentido, a nova experiência em ser portador do VHC poderá desencadear uma gama de conflitos e sentimentos que poderão modificar por completo a vida do indivíduo.

Diante dessa problemática, este estudo propôs-se a desvelar os sentimentos dos portadores de hepatite $\mathrm{C}$ relacionados à infecção e suas conseqüências. Tornar manifesto o que o portador do VHC traz implícito na árdua peregrinação do diagnóstico ao tratamento da hepatite $\mathrm{C}$, constitui elemento essencial para a garantia da qualidade de atendimento individualizado, valorizando o ser humano como ser holístico em detrimento da visão reducionista e tecnocrática. Contrapondo a essa realidade, pouco tem sido escrito quanto a essa abordagem, o que ressalta o valor deste estudo e acresce à literatura.

\section{METODOLOGIA}

Trata-se de um estudo descritivo de abordagem qualitativa, desenvolvido em uma instituição pública de saúde especializada no atendimento a doenças infecto-contagiosas. Sediada na cidade de Goiânia-GO, essa instituição atua como centro de referência atendendo a demanda local e das demais cidades goianas e de outras localidades do país.

\section{Sujeitos da pesquisa}

O número de sujeitos informantes foi definido mediante a saturação ou exaustão dos dados contidos na entrevista, sendo representado por oito sujeitos participantes. Para a seleção dos mesmos empregou-se a amostragem não-probabilística, aplicando o processo de amostragem por conveniência, buscando selecionar uma amostra típica ou ideal em que os sujeitos apresentassem as características sociais do objeto em estudo. 
Os sujeitos foram selecionados mediante o cumprimento aos seguintes critérios de inclusão: possuir idade igual ou maior que 18 anos, estar em tratamento ou ter sido submetido, anteriormente, a tratamento para hepatite $\mathrm{C}$ ou estar realizando acompanhamento para avaliar a evolução clínica desta.

\section{Coleta de dados}

A coleta de dados foi executada no mês de agosto de 2007 em dias e horários diferenciados. Os sujeitos foram identificados mediante agendamento da consulta, sendo posteriormente abordados e encaminhados a uma sala onde foram esclarecidos sobre a execução e os propósitos da pesquisa, bem como o consentimento de sua participação. $\mathrm{O}$ ambiente foi previamente reservado para o estudo oferecendo silêncio, conforto e privacidade, de modo a não intimidar o sujeito-colaborador.

Os dados foram coletados mediante entrevista individual e os depoimentos foram gravados para posterior transcrição das falas, fornecendo base de dados sólida, bem como servindo de meio legal para atestar a validade destes. Como instrumento utilizou-se a entrevista semiestuturada, permitindo ao sujeito participante espontaneidade de pensamento expressando suas experiências dentro do foco temático colocado pelo investigador.

O corpo da entrevista foi estruturado em três temáticas: diagnóstico, dificuldades e perspectivas, sendo cada temática abordada inicialmente por uma vinheta que veio fornecer a base estrutural para a pergunta norteadora central de cada abordagem temática em estudo, buscando ainda atrair a atenção do sujeito informante para o objeto de interesse.

\section{Análise dos dados}

Após a transcrição das falas, os dados foram analisados pela técnica de análise de conteúdo temático que permite descrever o que está por trás das palavras ao se utilizar inferências obtidas a partir da codificação e categorização do conteúdo das mensagens. ${ }^{7}$ Nesse procedimento analítico identificam-se os núcleos de sentido, os quais em suas características similares compõem um conjunto de expressões que permitem a formação de categorias de análise. A partir dessa análise foram identificadas três categorias: sofrimento e impotência frente à infecção; luta e dificuldades enfrentadas e; a fé como força motivadora.

\section{Aspectos éticos da pesquisa}

Este estudo segue as premissas expressas na Resolução No 196/96 do Conselho Nacional de Saúde, que regulamenta a pesquisa envolvendo seres humanos. Foi previamente submetido à apreciação do Comitê de Ética em Pesquisa da UniEVANGÉLICA, que emitiu Parecer Consubstanciado favorável à sua execução sob Protocolo $\mathrm{N}^{\circ} 080 / 07$ e ofício $\mathrm{N}^{\mathrm{o}} 161 / 2007$ de 24 de julho de 2007. Todos os sujeitos assinaram o Termo de Consentimento Livre e Esclarecido dando anuência à sua participação.

\section{RESULTADOS E DISCUSSÃO}

Dos oito sujeitos participantes da pesquisa, cinco eram do sexo masculino. Três tiveram tratamento prévio contra o $\mathrm{VHC}$, em que apenas um obteve remissão da doença e outro estava no segundo tratamento. Destaca-se que dois pacientes estavam co-infectados com o HIV e um tinha como co-morbidade a hemofilia. Ainda, um paciente teve evolução da doença para cirrose hepática.

A partir da análise do conteúdo temático das falas desses sujeitos depreendemos os núcleos de sentido, dos quais emergiram três categorias de análise: sofrimento e impotência frente à infecção; luta e dificuldades enfrentadas e; fé como força motivadora. Entendendo que a subjetividade define as formas de pensar, perceber e agir no mundo é, então, pela subjetividade que o homem é concebido como possuidor de natureza e essência. Essa essencialidade do indivíduo o traduz como produtor e produto inacabado estando sempre em constante movimento. ${ }^{8}$ Considerando esse aspecto, o sofrimento do portador de hepatite C, as dificuldades por este enfrentadas e a fé que demonstra são atitudes, sentimentos, emoções e reações complementares estabelecendo cada uma, simultaneamente, a relação de causa e efeito. Notase que o sofrimento desses indivíduos tem origem, principalmente, nas dificuldades enfrentadas, ao passo que o enfrentamento dessas, culmina, muitas vezes, em angústia, tristeza e preocupação. E, essas mesmas dificuldades fazem com que esses indivíduos vejam na fé uma alternativa de apoio, conforto e esperança.

Ao se comparar esse resultado com o obtido em 2006, em uma pesquisa envolvendo portadores de Doença Pulmonar Obstrutiva Crônica (DPOC), ${ }^{9}$ fica evidente a semelhança entre o impacto causado por uma doença crônica de origem infecciosa com o de uma doença crônica adquirida. Em am- 
bas, as falas dos sujeitos, desvelam que as pessoas que convivem com a doença crônica independente da etiologia, encontram-se imersas em um vale de tristeza, sofrimento, incapacidade e fé.

\section{$1^{\text {a }}$ categoria: sofrimento e impotência frente à infecção}

Para a primeira categoria identificou-se os seguintes núcleos de sentido: solidão, medo, angústia, tristeza e incapacidade. Por ser uma infecção silenciosa, de curso lento e de prognóstico variável, percebe-se que os sujeitos da pesquisa, portadores de hepatite $C$, mostram-se preocupados e temerosos quanto ao futuro. Os sofrimentos estão associados ao momento do diagnóstico positivo e, em maior intensidade, aos efeitos colaterais do tratamento, principalmente com o interferon. Tais reações refletem para alguns em mudança de vida e alterações de papéis onde se sentem frágeis e impotentes frente à doença.

[...] foi criado assim uma barreira muito grande entre o convívio da família comigo, [...] eu saí do convívio da minha família, fui viver só [...]. Mas aí eles se confortam que eu tô bem [...] mas eles não quis abraçar minha causa com minha doença da hepatite não. Eu tô sozinho e Deus (S1).

[...] eu fiquei super preocupado [...] hoje fiquei sabendo pelo meu médico que a hepatite $C$ virou cirrose [...]. Tenho que conviver com ela com o resto da minha vida (S2).

Quando eu venho aqui (referindo-se à instituição) eu fico com medo. Que aí eu converso com um, converso com outro, então eu vejo assim a gravidade dessa doença [...]. Eu tenho medo de quando eu chegar assim, mais pra frente [...] (S4).

[...] eu num posso trabalhar mais né, inclusive eu fui encostado pelo INSS por causa da coluna [...]. O médico liberou; aí como eu tô fazendo tratamento da hepatite eles me encostaram pela hepatite, por causa desse efeito colateral que ele causa [...] eu choro de desesperado, não decisão que vai terminar ou quando terminar [...] tem que aguardar o que a médica tá decidindo [...] o que ela decidi tenho que aceitar [...] (S6).

$\mathrm{O}$ VHC é transmitido de maneira mais eficaz pela via parenteral. E, embora seja rara a documentação de transmissão pelas vias sexual, vertical e horizontal, estas não devem ser desconsideradas uma vez que em $20 \%$ a $40 \%$ dos casos não se consegue determinar o modo de contaminação, constituindo os clássicos casos esporádicos. ${ }^{6} \mathrm{Os}$ meios de transmissão do VHC são compartilhados por outras importantes infecções de transmissão parenteral como o HIV e o Vírus da Hepatite B (VHB), incorrendo freqüentemente em casos de co-infecção. Embora seja a hepatite C uma infecção devastadora e desafiadora, não porta consigo o estigma social que acompanha o HIV. Nesse aspecto, os participantes co-infectados demonstraram indiferença e subestimação quanto à hepatite $C$, preocupando-se mais com o HIV.

Pra mim não foi um choque tão grande não, porque o choque maior foi quando eu descobri que tinha HIV, [...] e ela veio junto com o HIV [...] superei até de boa porque eu... já tinha passado pelo trauma do HIV , [...] (S1).

[...] Pra mim foi café pequeno, porque perto do HIV! [...] porque eu descobri que tinha HIV entendeu, na mesma época, tudo junto, [...]. Eu só sabia que não tinha cura, [...] nunca me afetou em nada não, graças a Deus (S8).

Os sentimentos são intrínsecos à satisfação pessoal e emocional, ${ }^{9}$ mantendo relação direta com o modo e qualidade de vida. A qualidade de vida do indivíduo é resultante da associação de inúmeros fatores determinantes como o biológico, psicológico, espiritual, econômico e social. É um conceito subjetivo baseado na percepção individual. As atitudes e comportamentos, sejam elas individuais e/ou coletivas, são enredadas por sentimentos, emoções e percepções. Assim, as complexas (re)ações e interações emergentes são produtos do ser humano no mundo e diante do mundo, das coisas, da natureza e das outras pessoas. ${ }^{10}$ Nesta ótica, a qualidade de vida tem como base a percepção que o indivíduo doente tem do impacto da doença em seu bem-estar e a maneira com que este reage às limitações impostas pela doença. ${ }^{11}$ Torna-se imprescindível compreender os aspectos perceptivos, sensoriais, afetivos e emotivos ao traduzirem inquietações, ansiedades, expectativas e conflitos decorrentes da maneira singular de se encarar a vida. ${ }^{10}$

Sendo assim, fica evidente que o sofrimento do indivíduo portador de hepatite $\mathrm{C}$ surge conforme esse indivíduo infectado/doente processa as informações acerca de sua infecção, construindo uma representação desta e, em função dela regulando seu comportamento.

\section{$2^{a}$ categoria: luta e dificuldades enfrentadas}

Dificuldades com o tratamento, falta de recursos financeiros, mudança de vida e busca de informações são os núcleos de sentido dos quais emergiram a segunda categoria de análise. Do diagnóstico ao tratamento, o portador de hepatite 
C passa por uma verdadeira odisséia. Pelas falas dos participantes, esta odisséia é traduzida pelo percurso burocrático do serviço público, a centralização da assistência implicando deslocar-se para um centro de referência para tratamento/ acompanhamento, bem como os efeitos colaterais da terapêutica medicamentosa.

[...] Na primeira vez teve algumas dificuldades com exames, que não fazia aqui, [...] depois passou a fazer [...] começou o tratamento e teve os efeitos colaterais, tanto que foi interrompido da primeira vez com seis meses. [...] da primeira vez teve efeito mais forte que dessa segunda vez [...] O problema é grave de falta medicamento no (refere-se ao local onde pega o medicamento) [...] (S3).

[...] O tratamento mesmo já tem dois anos [...]. Eu tomo interferon e ribavirina. Sinto o efeito. E, a partir do momento que eu comecei a tomar o remédio eu já comecei a sentir o efeito colateral, que é náusea, dores, é eu sinto até hoje; dores no corpo, é dor de cabeça, nevralgia, [...] emoção da gente fica alta de mais; dá muita tristeza, dá vontade de chora, da vontade de sei lá. Fica assim, da desespero na gente [...] (S6).

[...] Teve muita dificuldade. Assim, da parte financeira também [...] eu tive que vim pra Goiânia várias vezes [...] foi um ano em tratamento [...]. Você vai num lugar aí diz que não é ali, você vai em ou tro diz que não é lá [...] normalmente é muito demorado [...]. Eu tomei [...] ribavirina e interferon [...]. Senti febre, dor de cabeça, tontura [...] agora eu retorno aqui de 6 em 6 meses [...] (S7).

[...] Porque pra você cuidar, você tem que fazer exame, e é uma burocracia danada pra você consegui uma vaga [...]. É uma tristeza (S8).

Estando a qualidade de vida enredada por uma trama emaranhada de conceitos biológicos, funcionais (status de saúde e de capacidade), sociais, psicológicos e econômicos, a saúde comunga da satisfação do bem-estar e da felicidade. ${ }^{12} \mathrm{~A}$ angústia e o sofrimento do portador de hepatite $\mathrm{C}$ tem origem em duas situações: nas alterações psicológicas e nas dificuldades impostas pelo tratamento. Quanto às alterações psicológicas estas são decorrentes do prognóstico sombrio e desconhecido da evolução clínica da infecção. Essa incerteza torna o indivíduo impotente e incapaz de decidir por si só, tendo como única alternativa o acompanhamento de forma expectante. No que concerne às dificuldades terapêuticas, os efeitos colaterais, a baixa resposta virológica e a baixa segurança terapêutica são os principais determinantes que efluem para o sofrimento do portador de hepatite $C$.
Ocorrendo a necessidade de tratamento, a única modalidade terapêutica aprovada pelo Food and Drug Administration é o interferon (seja na fórmula convencional ou peguilado), utilizado tanto sob a forma de monoterapia ou em associação com a ribavirina. ${ }^{13}$ Uma série de reações tóxicas está associada ao uso de interferon. Estas vão desde efeitos colaterais agudos (febre, mialgia, calafrios, artralgia, cefaléia, etc.) a efeitos crônicos como a fadiga, podendo ocorrer também alterações endócrinas, hematopoéticas, renais, oculares, e do sistema nervoso central (déficit cognitivo, depressão, irritabilidade e insônia). Quanto à ribavirina a teratogenecidade e a anorexia são os principais efeitos colaterais da droga. ${ }^{3-13}$

Alterações oculares são registradas em estudos de casos realizados em 2006, ${ }^{13-14}$ evidenciando que portadores do VHC em tratamento prolongado (por mais de dois anos) com interferon (convencional ou peguilado) estão suscetíveis ao desenvolvimento de retinopatias. Essas retinopatias ocorrem tanto pela má perfusão capilar da retina, devido à trombose de veia retiniana, como pela formação de exudatos algonodosos e/ ou pelo acometimento do nervo óptico.

A hepatite $C$ está também associada a alterações psiquiátricas como os quadros depressivos. Na vigência da infecção, a depressão secundária pode ter como fatores precipitantes as particularidades da infecção, embora estejam mais relacionadas aos efeitos colaterais desencadeados pelo tratamento com inferferon. ${ }^{15}$ Todas essas alterações dissipam-se após interrupção do tratamento.

O tratamento apresenta algumas restrições, sendo para a administração de interferon contraindicado em casos de depressão grave, cirrose descompensada, cardiopatia sintomática, convulsão não controlada, leucopenia e plaquetopenia. Já para a ribavirina contra-indica-se em casos de insuficiência renal crônica terminal, anemia, cardiopatia grave e gravidez. ${ }^{3}$

Sabe-se que a evolução da infecção é resultante da interação imunológica do indivíduo versus a ação do hospedeiro viral. E, que a diversidade de genótipos com suas propriedades mutagênicas influenciam decisiva e significativamente na indicação e na eficácia do tratamento. Essa particularidade leva, muitas vezes, à necessidade de acompanhamento expectante da infecção, baixa eficácia medicamentosa, casos recidivantes e até mesmo a indivíduos não respondedores ao tratamento. Essa realidade é uma das dificuldades em que o portador de hepatite 
C depara-se na luta contra o VHC e que o torna impotente frente à infecção.

O tratamento tem resposta eficaz em torno de $40 \%$ para os genótipos 1 e $76 \%$ nos genótipos 2 e $3 .{ }^{1}$ Destes, $20 \%$ tornam-se reativos um ano após a interrupção do tratamento, diminuindo para 5\% num período de cinco anos, essa reativação pode ser decorrente da conjugação de dois fatores: o genótipo viral e a especificidade e sensibilidade dos métodos diagnósticos utilizado. ${ }^{5}$ Frente a baixa eficácia, a pouca segurança terapêutica e os efeitos colaterais, o tratamento é indicado apenas nos casos de hepatite crônica com atividade inflamatória moderada ou intensa, associada à presença de septos de fibrose e com alterações séricas de aminotransferases. ${ }^{16}$

A luta contra a hepatite $C$ é uma árdua peregrinação que exige desses peregrinos persistência e determinação. Essa força motivadora encontra seu sustento no apoio de familiares e amigos, recebendo valiosa contribuição da crença religiosa e da espiritualidade, de onde surge a terceira categoria.

\section{$3^{a}$ categoria: a fé como força motivadora}

Esta categoria surgiu a partir dos núcleos de sentido esperança, fé e confiança em Deus. Mesmo com todas as dificuldades que sobrevêm aos sujeitos diagnosticados portadores de hepatite $\mathrm{C}$, dificuldades essas que aliciam ou mesmo intensificam angústias e sofrimentos, esses indivíduos encontram na fé uma motivação e razão de existir.

[...] Eu acho que o dia que eu tiver de saí desse plano aqui vai ser por vontade de Deus, não pelas minhas doenças não. [...] (S1).

Futuro meu tá nas mão de Deus, né! Deus queira que agora depois dessa aí (refere-se ao diagnóstico recebido de evolução para cirrose) [...] mas eu tenho muita esperança na minha vida [...] seja o que Deus quizé (S2).

[...] Só Deus que sabe, num espero nada assim de mal, de grave não, [...] mas aí só Deus que sabe (S5).

[...] a maioria dos pacientes, parece que de entre 60 a 70\% consegui a cura. Eu fui um desses [...] eu espero né que a partir de agora eu consigo manter esse nível que eu consegui (S7).

Ah! Espero do lado de Deus, só Deus [...] que sabe que vai ser da minha vida. Tenho medo não. Eu tenho muita fé em Deus [...]. Quem tem fé acabou (S8).

Embora a religiosidade e a espiritualidade estejam inter-relacionadas, estas se diferenciam. A religião pode ser definida como a adoção e vivência de crenças e práticas religiosas específicas adotadas por uma igreja ou instituição. Por vez, a espiritualidade é um fenômeno transcendental, individual e pessoal estabelecida por uma pessoa com um ser ou força superior em que se acredita, conferindo sentido à vida, possibilitando crescimento pessoal, sabedoria, equilíbrio e maturidade. ${ }^{17}$

Assim, o aspecto religioso/espiritual tem sido descrito como uma variável associada à qualidade de vida, em que a fé é uma mediadora para facilitar o lidar com situações de estresse e problemas da vida. É na fé que durante os processos de adoecimento os indivíduos buscam apoio, tanto para encontrar um significado para a enfermidade como pela tentativa de cura pela fé. ${ }^{12}$

No processo de enfrentamento, a religiosidade pode conferir efeitos positivos ou negativos, conforme influenciada pelo modo de lidar com os eventos estressores, pelas crenças e práticas religiosas envolvidas nesse processo. ${ }^{17}$ Por isso é preciso que se perceba como o indivíduo entende, interpreta e vive sua experiência, e ainda como ele relaciona esta vivência com sua fé e crença religiosa. Assim, exigem-se do cuidador sensibilidade espiritual, paciência e tolerância para perceber e acolher sentimentos controversos, sem necessariamente modificá-los e censurá-los, mas despertar e reforçar comportamentos e sentimentos positivos. ${ }^{18}$

Dessa forma percebe-se que, entre os indivíduos estudados, independente da cultura ou de credo religioso nota-se a importância da espiritualidade para o resgate à motivação e bemestar dessas pessoas, em que a busca de um Ser Superior e Supremo instiga a confiança, confere significado à vida e motiva a existência rumo a um desfecho favorável.

\section{CONSIDERAÇÕES FINAIS}

O resgate do ser humano como ser ativo de sua existência, exige compreendê-lo e respeitá-lo em sua totalidade e individualidade. De sua vivência e experiência cotidiana emergem valores, crenças, atitudes e sentimentos conforme sua percepção e concepção individual da realidade situacional.

O ser humano é produto da interação de um conjunto de sistemas onde o seu eu converge da interação entre os fatores biológico, sociológico, psicológico, econômico e espiritual. Nessa complexidade do ser humano é de grande valia a humanização em saúde. A humanização transcende a visão do sujeito como ser passivo, pressupõe considerar a individualidade e a essência do ser 
humano, tendo a subjetividade como a base de toda intervenção. ${ }^{19-20}$

Nesse contexto, faz-se imprescindível a conscientização e sensibilização não só das pessoas que trabalham em saúde, mas da sociedade como um todo para que as pessoas, aqui os portadores de hepatite $\mathrm{C}$, possam ser compreendidas no processo do adoecer e encontrem o apoio necessário para o resgate da motivação.

Conviver com a infecção pelo VHC repercute numa gama de sofrimento para os portadores desse vírus, tanto pela patologia de base como pelas implicações terapêuticas. $\mathrm{O}$ sofrimento $\mathrm{e}$ impotência frente à infecção, as suas dificuldades e complicações esmaecem diante da fé, em que esses indivíduos encontram refúgio e uma busca alternativa para a cura.

Embora esses resultados sejam limitados aos sujeitos do estudo, não sendo plausível de generalização diante da subjetividade humana, possibilitaram-nos uma visão sobre a problemática de ser portador de hepatite $C$, contribuindo e ampliando o conhecimento nessa área ainda tão escassa. Novos estudos com essa abordagem são fundamentais e imperativos para o enriquecimento e compreensão da dimensão humana.

\section{REFERÊNCIAS}

1. Strauss E. Hepatite C. Rev Soc Br Med Trop. 2001 Jan-Fev; 34(1):69-82.

2. Zocrato KBF, Caiaffa WT, Proietti FA, CarneiroProietti AB, Mingoti AS, Ribeiro GJC, et al. HCV and $\mathrm{HIV}$ infection and co-infection: injecting drug use and sexual behavior, AJUDE-Brasil I Project. Cad Saúde Pública. 2006 Abr; 22(4):839-48.

3. Lopes E, Machado ER, Ferraz MLG, Hinrichsen SL. Hepatites virais. In: Hinrichsen SL. DIP-doenças infecciosas e parasitárias. Rio de janeiro (RJ): Guanabara Koogan; 2005. p.34-46.

4. Araújo ESA. Hepatite C. In: Cimerman S, Cimerman B. Condutas em infectologia. São Paulo (SP): Atheneu; 2004. p.113-21.

5. Conte VP. Hepatite Crônica por vírus C parte 2. Tratamento. Arq Gastroenterol. 2000 Out-Dez; 37(4):235-40

6. Conte VP. Hepatite Crônica por vírus C parte 1. Considerações gerais. Arq Gastroenterol. 2000 JulSet; 37(3):187-93.
7. Bardin L. Análise de conteúdo. $3^{\mathrm{a}}$ ed. Lisboa (PT): Ed.70; 2004.

8. Coimbra C, Leitão MBS. Das essências às multiplicidades: especialismo psi e produções de subjetividades. Psicol Soc. 2003 Jul-Dez; 15(2):6-17.

9. Kerkoski E, Borenstein MS, Gonçalves LO, Francioni FF. Grupo de convivência com pessoas com doença pulmonar obstrutiva crônica: sentimentos e expectativas. Texto Contexto Enferm. 2007 AbrJun; 16(2):25-32.

10. Gàspari JCde, Schwartz GM. O idoso e a ressignificação emocional do lazer. Psic.: Teor e Pesq. 2005 Jan-Abr; 21(1):69-76.

11. Matos APS, Machado ACC. Influência das variáveis biopsicossociais na qualidade de vida em asmáticos. Psic.: Teor e Pesq. 2007 Abr-Jun; 23(2):139-48.

12. Panzini RG, Rocha NS, Bandeira DR, Fleck MP de A. Qualidade de vida e espiritualidade. Rev Psiq Clín. 2007; 34(Supl 1):105-15.

13. Ávila MP, Freitas AM, Isaac DLC, Bastos ALM, Pena RV. Retinopatia em paciente portador de hepatite $\mathrm{C}$ tratado com interferon peguilado e ribavirina: relato de caso. Arq Bras Oftalmol. 2006 Mar-Abr; 69(2):255-59.

14. Helal Júnior J, Zacharias LC, Alencar LM. Trombose de veia central da retina em paciente usuária de interferon e ribavirina: relato de caso. Arq Bras Oftalmol. 2006 Jul-Ago; 69(4):601-04.

15. Horimoto FC, Ayache DCG, Souza JÁ. Uso de escitalopram em paciente com depressão secundária. Rev Psiquiatr. 2004 Set-Dez; 26(3):337-40.

16. Lyndsay KL, Hoofnagle JH. Hepatite crônica. In: Goldman L, Ausielo D. Cecil, tratado de medicina interna. 22 ${ }^{\mathrm{a}}$ Ed. Rio de Janeiro (RJ): Elsevier; 2005. p.1061-70.

17. Faria JB, Seidl EMF. Religiosidade e enfrentamento em contextos de saúde e doença: revisão da literatura. Psic Refl Crít. 2005 dez; 18(3):387-89.

18. Kovács MJ. Espiritualidade e psicologia - cuidados compartilhados. O mundo da saúde. 2007 Abr-Jun; 31(2):246-55.

19. Simões ALA, Rodrigues FR, Tavares DMS, Rodrigues LR. Humanização na saúde: enfoque na atenção primária. Texto Contexto Enferm. 2007 Jul-Set; 16(3):439-44.

20. Beck CLC, Gonzales RMB, Denardin JM, Trindade LL, Lautert L. A humanização na perspectiva dos trabalhadores de enfermagem. Texto Contexto Enferm. 2007 Jul-Set; 16(3):503-10. 